\title{
Assessment of sense of taste in Italian centenarians
}

\author{
The Italian Multicentric Study on Centenarians ${ }^{1,2}$
}

Received 7 July 1997; received in revised form 8 October 1997; accepted 20 November 1997

\begin{abstract}
The Italian multicentric study on centenarians (IMSC) was aimed at assessing the level of preservation of the sense of taste, and at estimating to what extent the recognition of various gustative stimuli can give satisfaction and information regarding the surrounding environment for the centenarians. Taste sensitivity has been qualitatively established in a group of 126 Italian centenarians (mean age 101.9 \pm 1.4 years) and compared to that of a group of 100 elderly subjects (mean age $70.5 \pm 5.0$ years). All the individuals included in the study groups had a mini mental state examination (MMSE) score larger than 19. The results revealed that taste sensitivity is significantly reduced in the centenarians; as a matter of fact, the elderly control subjects are able to perceive taste stimuli in $84.25 \pm 3.40 \%$ of the testing, while the centenarians were successful only in $74.23 \pm 6.19 \%$ of the experiments $(P<0.001)$. Furthermore, elderly subjects can correctly recognize taste stimuli in $70 \%$ of the testings, while correct recognition amounted only to $49.25 \%$ in cases of centenarians assessed. In spite of these differences between the elderly and centenarians, the latter are still able to perceive and recognize taste stimuli adequately, and as a consequence, are able to obtain information on tastes and receive a sufficient sensory stimulation through the tasting pathway. (C) 1998 Elsevier Science Ireland Ltd. All rights reserved.
\end{abstract}

Keywords: Centenarians; Elderly; Aging; Sense of taste

\footnotetext{
${ }^{1}$ The participants in the Multicentric Study are listed in Appendix A.

${ }^{2}$ Address for correspondence: Luciano Motta, Department of Internal Medicine and Geriatrics, Cannizzaro Hospital, Via Messina 829, 95126 Catania, Italy.
}

0167-4943/98/\$19.00 (C) 1998 Elsevier Science Ireland Ltd. All rights reserved.

PII S0167-4943(97)00041-1 


\section{Introduction}

The record for maximum life span in humans is held by the 122-year-old French woman Jeanne Calmant (Guinnes dei primati, 1997) who has died recently. The life span is determined almost certainly by genetic factors and is influenced by numerous, difficult to assess, environmental and socioeconomic factors. The great Elders age, but retain their homeostatic mechanisms, and this fact is currently one of the most interesting aspects in the field of geriatric research. Although it is actually impossible to interfere with genetic programs, longevity is markedly influenced by all the exogenous factors, like pathogenic agents, diet, lifestyle, physical activity, and psychosocial factors, which are able to alter the realization of the individual genetic programs.

Numerous university departments, geriatric and gerontologic units established the Italian multicentric study of centenarians (IMSC, 1995), co-ordinated by L. Motta, G. Receputo and C. Franceschi, aimed at studying the living conditions of Italian centenarians. Only scarce data are available in the literature on the centenarians, and our study furnished a precise profile of this population and confirmed the rectangularization of the survival curve. The IMSC group assessed socioeconomic, clinical, biological and behavioural aspects, including sensory information which is of great importance, since it regulates emotional, mnemonic and learning functions underlying various behavioural models. The fact that sensory pathways represent the only communication pathway between humans and the environment suggest the investigation of these pathways in centenarians, in order to evaluate if, and to what extent, these subjects can communicate with the environment. The present study describes the sense of taste in centenarians.

Humans perceive four main tastes: salty, sweet, sour and bitter. Taste is linked to the presence of chemoreceptors on the surface of the tongue which are stimulated by chemical substances. Taste receptors are represented by about 10000 taste buds contained in the filiform and fungiform papillae which are mainly found on the tongue. The impulses generated in the taste receptors are transmitted to the nucleus tractus solitaris in the spinal bulb along the facial, glossopharyngeal and the vagus nerves (Testut and Latarjet, 1971). The gustative messages pass through the medial lemniscus to the ventroposteromedial nuclei of the controlateral hypothalumus, and then continue to the lowest part of the postcentral gyrus of the parietal lobe in the anterior insular opercular cortex. Lesions in these areas determine reduced gustative sensitivity and stimulation to awake subjects induces gustative sensations. According to some scientists, the two gustative areas appear to have different functions: the parietal area may be responsible for localizing the gustative stimuli, while the anterior insular opercular, one seems to discriminate the quality of tastes (Manni, 1982). Literary data on sensory pathways in the oldest old population are rather scarce (Schiffman, 1977; Ordy and Brizzee, 1979; Baldelli et al., 1987a; Receputo et al., 1996). In order to complete this sort of information, we have conducted a double-aimed study: (1) to assess whether the sense of taste is preserved in 
centenarians at all, and if yes, to what extent; and (2) whether recognition of various gustative stimuli can give satisfactory information on the environment.

\section{Subjects and methods}

A census conducted from March to December, 1993, throughout the Italian territory, evaluated a population of 16541202 inhabitants, equal to about $29.02 \%$ of the total population. This census personally contacted and recorded 1162 centenarians (938 females and 234 males). Of this population, 382 (302 females and 80 males; age range 100-109 years, mean age $101.3 \pm 1.9$ years) were randomly selected. The cognitive performance of this group was estimated by the MMSE (Folstein et al., 1975):126 centenarians (100 females and 26 males; mean age $101.9 \pm 1.4$ years) reached a score larger than 19 , which is necessary to perform the taste test. The threshold value of 19 was taken as a reference, since it is considered to be valid for the Italian population, offering a sensitivity of $100 \%$ and a specificity of $95 \%$ (Valente et al., 1992). The results of centenarians were compared with those obtained in a control group of 100 elderly subjects (52 females and 48 males; age range $67-76$ years, mean age $70.5 \pm 5.0$ years) having a MMSE score larger than 19.

The taste tests were carried out during the morning time at the homes of the centenarians, while the control elderly subjects were tested at the hospital centers. The four main tastes were always presented to the studied individuals using the listed substances in the following order: (1) sweet: $32 \mathrm{~g} / 1$ sucrose in distilled water; (2) sour: $3.2 \mathrm{~g} / 1$ tartaric acid in distilled water; (3) salty: $8 \mathrm{~g} / 1$ sodium chloride in distilled water; and (4) bitter: $0.016 \mathrm{~g} / 1$ quinine sulfate in distilled water. Between the main tastes blanks of distilled water were applied.

\subsection{Taste recognition tests}

The tests were conducted on fasting subject who had not smoked or drank at least during the last hour. Moreover, he/she had been invited to rinse out his/her mouth with deionized water immediately before the test. Some characteristics were kept constant in order to avoid any bias of the subject, e.g. identical containers were used for the various test substances, the samples were served at room temperature and given in the same order. Moreover, the observers presenting the samples remained as neutral as possible. The subject received $10 \mathrm{ml}$ solution of the test substance and was then asked whether he/she had perceived any taste. The answers were classified as perception of taste (if the answer correctly indicated the presence of any taste) and recognition (if the answer correctly indicated the quality of taste as well) (Baldelli et al., 1987b; Receputo et al., 1996). The recognition score scale ranged from 0 (no correct recognition) to 4 (1-4 correct recognitions of the four tested taste). The substances were given at 10-min intervals and were interchanged with blank tests.

Statistical analysis was performed using Student's $t$-test for unpaired data. 
Table 1

Summary of the results on the perception of taste stimuli

\begin{tabular}{|c|c|c|c|c|c|c|}
\hline \multirow[t]{2}{*}{ Taste quality } & \multicolumn{3}{|l|}{ Perceived } & \multicolumn{3}{|c|}{ Non-perceived } \\
\hline & Total $(n)$ & $\mathrm{F} / \mathrm{M}$ & $(\%)$ & Total $(n)$ & $\mathrm{F} / \mathrm{M}$ & $(\%)$ \\
\hline \multicolumn{7}{|c|}{ Control elderly (100 subjects) } \\
\hline Sweet & 89 & $48 / 41$ & 89 & 11 & $4 / 7$ & 11 \\
\hline Salty & 81 & $46 / 35$ & 81 & 19 & $6 / 13$ & 19 \\
\hline Sour & 83 & $47 / 36$ & 83 & 17 & $5 / 12$ & 17 \\
\hline Bitter & 84 & $42 / 42$ & 84 & 16 & $10 / 6$ & 16 \\
\hline Group mean \pm S.D. & $84.25 \pm 3.40$ & & & $15.79 \pm 3.40$ & & \\
\hline \multicolumn{7}{|c|}{ Centenarians (126 subjects) } \\
\hline Sweet & 105 & $84 / 21$ & 83.3 & 21 & $16 / 5$ & 16.7 \\
\hline Salty & 89 & $70 / 19$ & 70.6 & 37 & $30 / 7$ & 29.4 \\
\hline Sour & 92 & $70 / 22$ & 73 & 34 & $30 / 4$ & 27 \\
\hline Bitter & 88 & $71 / 17$ & 70 & 38 & $28 / 10$ & 30 \\
\hline Group mean \pm S.D. & $74.23 \pm 6.19$ & & & $25.77 \pm 6.19$ & & \\
\hline
\end{tabular}

Percentages are expressed in the total study population group.

$\mathrm{F} / \mathrm{M}$ Female/male ratio.

\section{Results}

Centenarians' perceptive capacity was well conserved as an elevated percentage furnished correct answers. In fact, $83.3 \%$ of the 126 subjects tested perceived, but did not recognize, the sweet taste, $70.6 \%$ the sour taste, $73 \%$ the salty and $70 \%$ the bitter taste. The results showed that perception of the sweet taste prevailed, even if the difference between responses was not significant. Furthermore, a high and homogeneous percentage of subjects correctly perceived the three blanks $(76.5,74$ and $78 \%$, respectively), revealing that centenarians perceive taste stimuli. Positive responses according to sex did not show any great differences between males and females (males $76 \%$ vs. females $74 \%$ ) (Table 1).

Correct recognition of the gustative stimuli (sweet, salty, sour, bitter) $(49.25 \%)$ was lower than mere stimulation (74.23\%) (Table 2) as recognition of any sensory stimulus implies cortical activity involving cognitive functions that are only par-

Table 2

Comparison between centenarians' and elderly subjects' capacity to recognize taste stimuli

\begin{tabular}{lccc}
\hline & \multicolumn{1}{c}{ Elderly } & P & Centenarians \\
\hline Score range & $0-4$ & & $0-4$ \\
Mean score & $2.36 \pm 0.64$ & $<0.001$ & $1.41 \pm 1.74$ \\
Correct recognition (\%) & $70.02 \pm 4.52$ & $<0.001$ & $49.25 \pm 4.27$ \\
Wrong recognition (\%) & $24 \pm 3.41$ & $<0.001$ & $32.0 \pm 5.74$ \\
No answer (\%) & $6.0 \pm 2.19$ & $<0.001$ & $18.75 \pm 1.9$ \\
\hline
\end{tabular}


tially used in perceptive activity. It is evident that more people perceive a stimulus, than recognize it. Nevertheless, our results revealed that a sufficient number of centenarians were capable of recognizing a perceived taste stimulus accurately. This was true for all the substances (54\% for sweet stimulus, $44 \%$ for sour, $51 \%$ for salty and $48 \%$ for bitter). Grouping into age and sex classes revealed a non significant increase in the number of males who recognized the stimuli (51\% vs. $47.5 \%)$. Our study series seemed to have the greatest difficulty in recognizing the sour taste.

As shown in Table 1, the overall perceptive capacity of the elderly controls was rather high $(84.25 \%)$ and it is quite well conserved even in the centenarians $(74.23 \%)$. Accordingly, the values for the missed perception scores amounted to 15.75 and $25.77 \%$ in the controls and centenarians, respectively.

As regards the correct recognition of the given tastes, the scores are considerably lower in both the elderly controls and the centenarians (elderly: 70\%; centenarians: $49.25 \%$ ). In the elderly controls, the mean score was $2.36 \pm 0.64$, whereas, the centenarians displayed a mean score of only $1.41 \pm 1.74$.

\section{Discussion}

Comparison of the results of the taste recognition test obtained in the centenarians with those observed in the elderly subjects revealed that taste recognition was significantly reduced $(P<0.001)$ in the former (Table 2$)$.

Our data showed that taste was sufficiently preserved in our centenarian population and was still a possible source of information and pleasure in very old age, even if recognition of taste stimuli was significantly reduced. It is difficult to establish the causes of this reduction in centenarians, even if the following hypothesis can be put forward: (1) the reduction may be determined by physiological age-related processes involving the chemoceptors, nuclei and taste pathways; and (2) the occurrence of ischemic or hemorrhagic events of the taste pathways and/or cerebral nuclei during aging. This is supported by data from an autopsy study on 141 centenarians in the Trieste Region (IMSC, 1995) which revealed an elevated number of cerebrovascular diseases $(33 \%)$.

\section{Appendix A}

There were 20 University Centers who collaborated in the IMSC. This report was made possible by their enthusiastic co-operation in preparing the case sheets, recording the series and data processing.

The success of the IMSC must be shared equally among all the members of study centers.

G. Baggio, M. Dalla Vestra, S. Donazzan, Institute of Internal Medicine, Via Giustiniani 2 35128, University of Padova.

G. Barbagallo Sangiorgi, M. BarbagalloG. Fradà, Institute of Internal Medicine and Geriatrics, Via Del Vespro 141, 90144, University of Palermo. 
S. Bertolini, M. Agretti, P. Costelli, Department of Internal Medicine, Viale Benedetto XV 6, 16132 Genova, University of Genoa.

E. Bosi, M. Manzoni, F.B. Tomasello, Scientific Institute Ospedale S. Raffaele, Via Olgettina 60, 20132, University of Milan.

A. Capurso, A.M. Colacicco, V. Solfrizzi, Institute of Geriatrics, Piazza G. Cesare 11, 70124 Bari, University of Bari.

F. Fabris, G. Cappa, E. Ferrario, Institute of Geriatrics, Ospedale Molinette, Corso Bramante 88, 10126 Torino, University of Turin.

S. Forconi, M. Guerrini, S. Boschi, Institute of Semeiotics and Geriatrics, Nuovo Policlinico 'Le Scotte', Viale Bracci, 53100, University of Siena.

C. Franceschi, A. Cossarizza, D. Monti, Department of Biomedic Sciences Via Campi 287-41100 Modena, University of Modena.

A. Gaddi, S. D'Addato, C. Galletti, Department of Clinical Medicine and Biotecnology, Policlinico S. Orsola, Via Massarenti 9-40138 Bologna, University of Bologna.

L. Giarelli, F. Cavalieri, G. Stanta, Institute of Anatomopathology, Ospedale Maggiore, Via Stuperich 1, 34125 Trieste, University of Trieste.

D. Mari, F. Duca, P. Ferrazzi, Department of Internal Medicine, Via Pace 9, Milano, University of Milan.

V. Marigliano, C. Bauco, M. Cacciafesta, Institute of Gerontology and Geriatrics, Viale del Policlinico Umberto I, 00161, University La Sapienza, Rome.

G. Masotti, N. Marchionni, E. Petruzzi, Institute of Gerontology and Geriatrics, Ospedale Ponte nuovo, Via Oblate 4, 50134 Firenze, University of Florence.

R. Mattace, M. Motta, L. Pansini, Department of Experimental and Clinical Medicine, Policlinico 'Mater Domini'-Via T. Campanella, 88100 Catanzaro, University of Catanzaro.

L. Motta, R. Rapisarda, G. Receputo, Department of Internal Medicine and Geriatrics, Ospedale Cannizzaro, Via Messina 829, 95126 Catania, University of Catania.

M. Passeri, F. Fagnoni, P. Sansoni, Institute of Clinical Medicine, Ospedale di Parma, Via Gramsci 14, 43100, University of Parma.

G. Salvioli, M.V. Baldelli, M. Neri, Department of Geriatrics, Ospedale Estence, Viale Vitt. Veneto 9, 41100 Modena, University of Modena.

U. Senin, A. Cherubini, M.C. Polidori, Institute of Gerontology and Geriatrics, Via Euglubina 42, 06122, University of Perugia.

M. Trabucchi, S. Boffelli, R. Rozzini, Geriatric Research Group, Ospedale Richiedei, Via Pinidolo 23, 25064 Gussago, Brescia.

M. Varricchio, A. Gambardella, G. Paolisso, Department of Gerontology and Geriatrics, Piazza Miraglia, Napoli, University of Naples.

\section{References}

Baldelli, M.V., Ballotti, A., Siligardi, E., Zappelli, D., Toschi, A., Neri, M., Vecchi, G.P., 1987. Le alterazioni geusiche nell'anziano. In: Pavoni, E. (Eds.), Invecchiamento tra paura e desiderio. Idelson, Napoli, pp. 77-82 (in Italian). 
Baldelli, M.V., Siligardi, L., Neri, M., Vecchi, G.P., 1987. Interpretation of enviromental stimuli in the very old. Abstract of 3rd Congr. IPA, Chicago, p. 123.

Folstein, M.F., Folstein, S.E., McHugh, P.R., 1975. Mini mental state. A pratical method for grading the cognitive state of patients for the clinicians, J. Psychiatr. Res., 33, 228-235.

Guinnes dei primati, 1997. Mondadori 80, Milano (in Italian).

Italian Multicentric Study on Centenarians, 1995. I centenari in Italia: aspetti epidemiologici e clinico-biologici. Atti del $96^{\circ}$ Congr. Medicina Interna, 12-15 Ottobre 2, 117-218 (in Italian).

Manni E., 1982. Il neurone. In: Rindi, G., Manni, E. (Eds.), Fisiologia Umana, vol. I. UTET, Torino, pp. 170-178 (in Italian).

Ordy, J.M., Brizzee, K.R., 1979. Sensory System and Comunication in the Elderly. Aging Series, vols.10, 13. Raven, New York, p. 13.

Receputo, G., Mazzoleni, G., Di Fazio, I., Alessandria, I., Savia, S., Scarpinato, R.A., Tomasello, F.B., Laurino, A., Fornaro, D., 1996. Study on the sense of taste in a group of Sicilian centenarians, Arch. Gerontol. Geriatr., (Suppl. 5), 411-414.

Schiffman, S., 1977. Food recognition by the elderly. J. Gerontol., 32, 586.

Testut, L., Latarjet, A., 1971. Organi di senso. In: Testut, L., Latarjet, A. (Eds.), Anatomia Umana, vol. 4. UTET, Torino, pp. 515-518 (in Italian).

Valente, C., Maione, P., Lippi, A., 1992. Validazione del mini mental test examination come strumento di screening per la demenza in una popolazione italiana, G. Gerontol., 40, 161-65 (in Italian). 